\title{
Predifferentiated GABAergic neural precursor transplants for alleviation of dysesthetic central pain following excitotoxic spinal cord injury
}

\author{
Jeung Woon Lee ${ }^{1,2}$, Stanislava Jergova ${ }^{1,3}$, Orion Furmanski ${ }^{1,4}$, Shyam Gajavelli ${ }^{1}$ and Jacqueline Sagen ${ }^{1}$ * \\ ${ }^{1}$ Miami Project to Cure Paralysis, Miller School of Medicine, University of Miami, Miami, FL, USA \\ 2 Department of Biology, William Paterson University, Wayne, NJ, USA \\ ${ }^{3}$ Institute of Neurobiology, CE, Slovak Academy of Sciences, Kosice, Slovakia \\ ${ }^{4}$ Department of Anesthesiology and Critical Care Medicine, Johns Hopkins School of Medicine, Baltimore, MD, USA
}

\section{Edited by:}

Alexander Rabchevsky, University of Kentucky, USA

Reviewed by:

Luciana Campos, University Camilo

Castelo Branco, Brazil

Dasa Cizkova, University of Veterinary

Medicine and Institute of

Neurobiology SAS, Slovakia

\section{*Correspondence:}

Jacqueline Sagen, The Miami Project to Cure Paralysis, Miller School of Medicine, University of Miami, 1095 NW 14 $4^{\text {th }}$ Terrace, R-48, Miami, FL 33136, USA.

e-mail: jsagen@miami.edu
Intraspinal quisqualic acid (QUIS) injury induce (i) mechanical and thermal hyperalgesia, (ii) progressive self-injurious overgrooming of the affected dermatome. The latter is thought to resemble painful dysesthesia observed in spinal cord injury (SCI) patients. We have reported previously loss of endogenous GABA immunoreactive (IR) cells in the superficial dorsal horn of QUIS rats 2 weeks post injury. Further histological evaluation showed that GABA-, glycine-, and synaptic vesicular transporter VIAAT-IR persisted but were substantially decreased in the injured spinal cord. In this study, partially differentiated GABA-IR embryonic neural precursor cells (NPCs) were transplanted into the spinal cord of QUIS rats to reverse overgrooming by replenishing lost inhibitory circuitry. Rat E14 NPCs were predifferentiated in $0.1 \mathrm{ng} / \mathrm{ml} \mathrm{FGF-2} \mathrm{for} 4 \mathrm{~h}$ prior to transplantation. In vitro immunocytochemistry of transplant cohort showed large population of GABA-IR NPCs that double labeled with nestin but few colocalized with NeuN, indicating partial maturation. Two weeks following QUIS lesion at T12-L1, and following the onset of overgrooming, NPCs were transplanted into the QUIS lesion sites; bovine adrenal fibroblast cells were used as control. Overgrooming was reduced in $>55.5 \%$ of NPC grafted animals, with inverse relationship between the number of surviving GABA-IR cells and the size of overgrooming. Fibroblast-control animals showed a progressive worsening of overgrooming. At 3 weeks post-transplantation, numerous GABA-, nestin-, and GFAP-IR cells were present in the lesion site. Surviving grafted GABA-IR NPCs were $\mathrm{NeuN}^{+}$and GFAP ${ }^{-}$. These results indicate that partially differentiated NPCs survive and differentiate in vivo into neuronal cells following transplantation into an injured spinal cord. GABA-IR NPC transplants can restore lost dorsal horn inhibitory signaling and are useful in alleviating central pain following SCl.

Keywords: cortical progenitor cell, quisqualic acid, spinal cord injury, GABA, transplantation, neuropathic pain, VIAAT, overgrooming

\section{INTRODUCTION}

Pain is a major complication in patients with spinal cord injury (SCI) where conventional pharmacological, electrical, or psychological treatments provide only minor and temporary relief (Finnerup et al., 2002; Finnerup and Jensen, 2004; WiderstromNoga et al., 2008; Siddall, 2009; Kwon et al., 2010; Mann et al., 2010). Mechanisms involved in the establishment of SCI pain are still not fully understood due to difficulties in dissociating traumatic cascade of events occurring in the spinal cord to those arising from the dorsal root ganglia, sympathetic ganglia, and peripheral nerves (O'Brien et al., 1994; Bethea et al., 1998; Miranda et al., 1999; Springer et al., 1999; Yaksh et al., 1999; Saito et al., 2000; Bruce et al., 2002; Hains et al., 2003b; Hoheisel et al., 2003). Furthermore, biochemical events leading to abnormal firing of spinal neurons (Mills et al., 2001; Yezierski et al., 2004), up-regulation of voltage-gated ion channels (Nashmi and Fehlings, 2001; Edwards et al., 2002; Hains et al., 2003a), recruitment of reactive glia
(Carlton et al., 2009), and excessive release of excitatory amino acids (excitotoxicity) in the spinal gray and white matters add to the complexity of neuropathic pain in SCI patients (Mills et al., 2001; Zeilig et al., 2012).

Excitotoxicity-induced SCI model using intraspinal injections of the AMPA- and metabotropic glutamate receptor agonist quisqualic acid (QUIS) have been described by Yezierski et al. (Yezierski et al., 1993, 1998; Gorman et al., 2001). QUIS can produce more controlled-lesion with characteristic neuronal loss, demyelination, cavitation, glial activation, perivascular changes, breakdown of the blood-brain barrier, and inflammation, closely mimicking sequence of events observed in contusion or ischemic injured spinal cords. QUIS injured rats exhibit nociceptive behaviors for mechanical and cold allodynia and selfinjurious overgrooming behaviors (Brewer and Yezierski, 1998; Gorman et al., 2001). Overgrooming behavior is thought to be mediated by dysesthetic sensations originating from the affected 
at-level dermatomes and/or DRGs ipsilateral to insult (Brewer et al., 2008), and disruption of inhibitory tone maintained by endogenous GABAergic neurons in the superficial dorsal horn (Lee et al., 2008). QUIS injury also up-regulates ERK1/2, TNF- $\alpha$, and cytokines known to be involved in molecular events leading to development of nociception (Yu and Yezierski, 2005; Brewer and Nolan, 2007).

Loss of endogenous GABA-IR cells following QUIS or CNS/PNS injuries may play an important function in modulating nociception (Zhang et al., 1994; Lee et al., 2008), yet their role remains elusive (Polgar et al., 2003; Polgar and Todd, 2008). Chronic constriction injury in rats induce increased number of picnotic cells, hyperchromatic "dark neurons" possibly indicative of transsynaptic degeneration in the superficial spinal or medullary dorsal horn, in the superficial dorsal horn by one week post injury (Ibuki et al., 1997), and spared nerve injury decreases primary afferent-induced IPSCs in lamina II neurons, presumably due to the loss of GABA resulting from decreased GAD 65 expression (Moore et al., 2002). Such injury-induced nociceptive behaviors can be further exacerbated by pharmacologic blockade of inhibitory neurotransmission (Sugimoto et al., 1987, 1990; Hama and Sagen, 1993). In stereological estimates from EM sections, excitotoxic neuronal cell death in the superficial dorsal horn was also observed in sciatic nerve-lesioned animals following stimulation of A fibers (Coggeshall et al., 2001), and cell death in the superficial dorsal horn (TUNEL labeling) has been observed following CCI and sciatic neurectomy which could be prevented by NMDA antagonists and caspase inhibitors (Azkue et al., 1998; Whiteside and Munglani, 2001; Scholz et al., 2005). Nerve injuryinduced nociceptive behaviors can be reversed by the administration of GABA into the spinal cord (Eaton et al., 1999a; Sokal and Chapman, 2003). Intrathecal administration of baclofen or muscimol, GABA receptor agonists, cause dose-dependent analgesia in animals with peripheral nerve injury (Hwang and Yaksh, 1997), and these effects were blocked with the administration of GABA receptor antagonist bicuculline suggesting specificity of GABA on reducing noxious sensation (Malan et al., 2002).

Recently, several reports showed possible therapeutic use of transplanting embryonic neural cells to control central and peripheral nociceptive behaviors. Intraspinal transplantation of mouse embryonic neural stem (ES) cells can reverse QUISinduced formalin and mechanical nociception (Hendricks et al., 2006). Intraspinal and intrathecal injections of predifferentiated GABAergic embryonic ES cells (human and rodent-derived) can also reverse CCI/SNL-induced nociceptive behaviors (Mukhida et al., 2007; Jergova et al., 2012), possibly by rescuing the endogenous inhibitory neural circuitry (Vaysse et al., 2011). GABAergic neuronal stem cells (hSSC, hNT, and mouse ES) have been used to control pain arising from ischemic paraplegia as well as spinal hemisection-induced nociception (Marsala et al., 2004; Cizkova et al., 2007; Kim et al., 2010). Although it is not clear how the embryonic cells achieve anti-nociception (via local secretion of GABA or rescuing of endogenous GABAergic/inhibitory mechanisms), transplantation of predifferentiated embryonic inhibitory neurons can modulate nerve injury-induced pain. The source of embryonic stem cells also may be of importance, as forebrainderived cells are reported to yield much higher density of
GABAergic cells than spinal cord-derived cells (Watanabe et al., 2004).

The present study examined effects of transplanting partially differentiated GABA-immunoreactive embryonic cortical precursor cells in quisqualic acid-lesioned rat spinal cord to reverse pain behavior. First, we looked at the pre-differentiation of cultured embryonic rat cortical neurospheres into GABAergic phenotype by exposing the neurospheres to varying concentrations of FGF-2. The second part of the experiment focused on transplantation of predifferentiated GABAergic neurospheres into the spinal cord of QUIS-lesioned animals for the alleviation of central pain, indirectly measured by changes in overgrooming area. Results of these experiments show transplantation of predifferentiated GABAergic neural precursor cells (NPCs) into the spinal cord of QUIS-lesioned animals prevents or reduces overgrooming behavior. Portions of this work have been presented previously in abstract form (Lee et al., 2001).

\section{MATERIALS AND METHODS ANIMALS}

Male Sprague Dawley rats (220-250 g, Charles River labs) were housed in a regular light condition (12:12 light and dark cycle) with food and water ad libitum. All experimental procedures were approved by the Institutional Animal Care and Use Committee (IACUC) of the University of Miami, Miller School of Medicine.

\section{QUISOUALIC ACID LESION}

All animals in the study received quisqualic acid lesion (QUIS, $125 \mathrm{mM}$, Sigma) at T12-L1 spinal level. QUIS was diluted in distilled water and aliquoted into $50 \mu \mathrm{l} / \mathrm{vial}$ and kept frozen $\left(-20^{\circ} \mathrm{C}\right)$ until use. Animals were anesthetized using 3\% isoflurane $/ \mathrm{O}_{2}$ and a midline dorsal skin incision was made to expose the thoracolumbar vertebrae. Laminectomy was performed to expose the spinal T12-L1 levels. Animals were placed on a spinal stereotaxic unit (David Kopf Inc., CA, USA), and dura was cut and retracted laterally to expose the dorsal root entry zones. QUIS was injected into the dorsal horn halfway between the dorsal vein and the dorsal root entry zone using a glass micropipette attached to a Hamilton syringe ( $10 \mu \mathrm{l}$, Reno, NV, USA). Using a microinjector, three injections of $0.4 \mu \mathrm{l}$ each of QUIS was injected into the spinal cord gray matter at a depth of $1 \mathrm{~mm}$. Injections were made unilaterally and spaced out at $500 \mu \mathrm{m}$ rostro-caudal direction (Figures 1B,C). Upon completion of each QUIS injection, the glass pipette was left in place for $60 \mathrm{~s}$ to prevent backflow. Muscle was closed to cover the injection site and the skin was closed with the wound clips.

\section{OVERGROOMING BEHAVIOR AND OVERGROOMING AREA MEASUREMENTS}

To measure changes in pain threshold before and after predifferentiated embryonic cell transplantation, the total skin overgrooming area of each animal was digitally photographed (Figure 1C) and then manually recorded by tracing the wound outline onto a semitransparent plastic film superimposed over the overgrooming site. The outlines on the film were digitally retraced with Neurolucida (MicroBrightField Inc., Williston, VT, USA) and the total overgrooming area was obtained. For each QUIS-lesioned animal, the total overgrooming area was measured in square millimeter 


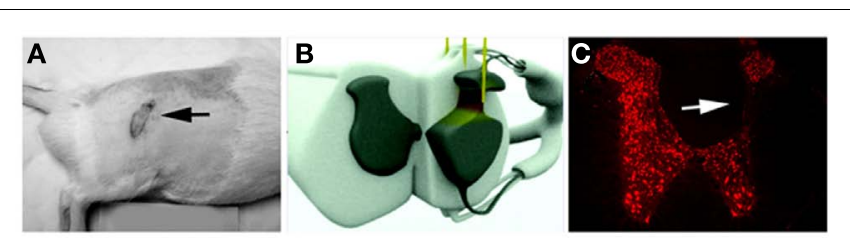

FIGURE 1 | Overgrooming lesions were primarily observed on at-level ipsilateral dermatomes two weeks after lesion [(A): black arrow]. (B) A 3D model of spinal cord showing three injections of approximate $1 \mathrm{~mm}$ in depth from the dorsal surface needed to induce overgrooming in QUIS animals. (C) Characteristic loss of spinal neurons (Neu-N immunoreactivity) in the neck of dorsal horn 2 weeks after QUIS injection (white arrow). Neurons from the superficial lamina I and II are mostly spared from the excitotoxic cell death.

before transplantation ( 2 weeks post-lesion) and every week since transplantation for 3 weeks up until the time of perfusion.

\section{ISOLATION OF NEURAL PROGENITOR CELLS}

Embryonic cortical neural progenitor cells were isolated from E14 Sprague Dawley rats. Pregnant rats were deeply anesthetized with an overdose of nembutal (Sodium pentobarbital, Abbott, MI, USA) and a midline ventral incision was made to expose the embryos. Lateral ganglionic eminence were dissected out and placed into a $15 \mathrm{ml}$ conical tube containing cold Hank's balanced salt solution (HBSS, pH 7.2; Gibco). Isolated cortical tissues were gently triturated mechanically to dissociate into single cells, resuspended and plated at low density $\left(3.5 \times 10^{6}\right.$ in $7 \mathrm{ml}$ of media $)$ in $\mathrm{N} 2$ growth media (DMEM/F12 + N2 supplement, pH 7.2; Gibco) containing standard concentration of FGF-2 (10 ng/ml, R\&D) at $37^{\circ} \mathrm{C}$. Embryonic precursor cells were grown as small neurospheres and passaged by high flow rate trituration every 3-4 days to maintain initial density. The N2 growth media was changed every 2 days, and additional $6 \mu \mathrm{l} \mathrm{FGF-2}(10 \mathrm{ng} / \mathrm{ml})$ was added into the media in between media changing days.

\section{IN VITRO PARTIAL DIFFERENTIATION OF RAT EMBRYONIC CORTICAL PRECURSOR CELLS INTO GABA-IMMUNOREACTIVE CELL TYPE}

Five to ten days old cultured neurospheres were transferred to $15 \mathrm{ml}$ tubes, centrifuged at $700 \mathrm{RPM}$ for $5 \mathrm{~min}$ at $4^{\circ} \mathrm{C}$, and resuspended in $\mathrm{N} 2$ culture media containing either $0.1,1$, or $10 \mathrm{ng} / \mathrm{ml}$ FGF-2. Neurospheres were incubated in these media for 4-16 h. Neurospheres were then resuspended in N2 culture media with $10 \mathrm{ng} / \mathrm{ml} \mathrm{FGF-2} \mathrm{maintaining} \mathrm{the} \mathrm{initial} \mathrm{density} \mathrm{of} \mathrm{approximately}$ $0.5 \times 10^{6}$ neurospheres $/ \mathrm{ml}$. Neurospheres were plated on a polyL-ornithine/fibronectin (Sigma Aldrich) coated plastic plates for 1 day and fixed with $4 \%$ paraformaldehyde to quantitate the number of precursor cells differentiated into GABAergic cells in vitro after exposure to different concentrations of FGF-2. Fixed cells were also processed for GABA, NeuN, nestin, GFAP, MAP-2, $\beta$-III-tubulin, and BrdU immunofluorescence.

\section{IN VITRO OUANTITATION OF GABA CONCENTRATION SECRETED BY THE EMBRYONIC PRECURSOR NEUROSPHERES}

The growth media of cell culture from original harvested cells (P0) and in vitro differentiated neurospheres (P1) were sampled to ascertain the concentration of GABA secreted by the precursor neurosphere cells. The neurospheres were not stimulated electrically/physically in any way to induce GABA secretion. Twenty microliters of growth media from both samples were collected every day for 7 days. The passage 0 cells survived up to 4 days post harvest whereas the passage 1 neurospheres were visibly healthy even at 12 days post harvest. High-Pressure Liquid Chromatography (HPLC) was used to measure the concentration of GABA present in $20 \mu \mathrm{l}$ growth media sample. Samples were analyzed on a chromatograph consisting of a Beckman Model 118 Solvent Module, a Beckman System Gold data system and an ESA Coulochem II electrochemical detector. A 150-mm long, 3-mm-diameter ESA C18 column was used. The mobile phase consisted of $1.5 \mathrm{mM}$ sodium octane sulfonic acid, $75 \mathrm{mM} \mathrm{NaH} 2 \mathrm{PO} 4$, triethylamine, and $10 \%$ acetonitrile dissolved in water at $\mathrm{pH} 3.0$.

\section{TRANSPLANTATION OF PREDIFFERENTIATED GABA-IMMUNOREACTIVE EMBRYONIC PRECURSOR CELLS OR CONTROL BOVINE FIBROBLAST CELLS IN QUIS RATS}

Only rats exhibiting overgrooming behavior 10-14 days postQUIS lesion received cell transplantation $(n=34)$. Animals were anesthetized and laminectomy was performed to expose the spinal level where the QUIS lesion was made (T12-L1). Using glass micropipette, three injections of $4 \mu \mathrm{l}$ each of neural progenitor cells $(50,000 \mathrm{cell} / \mu \mathrm{l}$, total 600,000 cells/animal) were injected into the dorsal horn, ipsilateral to QUIS lesion, at a depth of $0.5 \mathrm{~mm}$ to $1 \mathrm{~mm}(n=27)$. Controls were injected with bovine fibroblast cells $(n=7)$. Glass pipette was left in place for $60 \mathrm{~s}$ to prevent backflow of the cells, muscle was closed to cover the injection site, and the skin was closed with wound clips. Rats were immunosuppressed by cyclosporine A (i.p., $10 \mathrm{mg} / \mathrm{kg}$; Bedford Labs, OH, USA) from -1 day until sacrifice.

\section{IN VITRO AND SPINAL CORD IMMUNOHISTOCHEMISTRY}

Three weeks after cell transplantation, and after weekly measurements of overgrooming area, animals were anesthetized with an overdose of pentobarbital and perfused transcardially using a peristaltic pump. Animals were perfused with cold $0.9 \%$ saline followed by either cold $4 \%$ paraformaldehyde in $0.1 \mathrm{M}$ phosphate buffer (PB, pH 7.2) or $4 \%$ paraformaldehyde plus $1 \%$ glutaraldehyde in $0.1 \mathrm{M}$ PB. Spinal cords were removed and post-fixed in the same fixative overnight, then placed in $30 \%$ sucrose-PB solution for cryoprotection.

Predifferentiated neurospheres (in vitro) and NPC-transplanted QUIS spinal cords were processed for immunohistochemical analysis. The neurospheres (5-7 days old) were fixed with cold 4\% paraformaldehyde in Phosphate Buffered saline (PBS; $\mathrm{pH} 7.4$ ), and were incubated overnight in PBS with $0.4 \%$ Triton-X 100 and 5\% normal goat serum (PBS-TGS) containing the following primary antibodies: NeuN (1:300, mouse, Chemicon, MA, USA), GABA (1:200, guinea pig, Protos Inc., NY, USA), GFAP (1:200, mouse, Steinberg), nestin (1:10, mouse, rat401, Developmental Studies Hybridoma Bank, Iowa City, IA, USA), and $\beta$-III-tubulin (1:200, mouse, Chemicon, MA, USA). Depending on the double labeling schedule, cells were incubated with species-specific secondary antibodies conjugated with either AlexaFluor 488 or AlexFluor 594 (Molecular Probes, NY; 1:200 in PBS-TGS) for $2 \mathrm{~h}$ at room temperature. For BrdU labeling, fixed neurospheres were 
treated with $2 \mathrm{~N} \mathrm{HCl}$ for $10 \mathrm{~min}$, washed in PBS and incubated in Borate solution for $10 \mathrm{~min}$. After wash, cells were incubated in the blocking solution, primary and secondary antibody according to the protocol above. Some neurospheres were processed for GABA immunostaining using biotinylated secondary antibody, followed by incubation in avidin-biotin solution in PBS for $1 \mathrm{~h}$ and using $\mathrm{DAB}$ as a chromogen.

Spinal cord segments thoracic 10 to lumbar 5 were cut at $30 \mu \mathrm{m}$ using a freezing microtome (American Optical, MA, USA), rinsed in $\mathrm{PBS}$, and then treated for $1 \mathrm{~h}$ at room temperature in PBS-TGS. Sections were incubated overnight in PBS-TGS containing the following primary antibodies: NeuN, GABA, GFAP, nestin, and $\beta$-III-tubulin as described above. Spinal sections were washed $3 \times 10 \mathrm{~min}$ in cold PBS-TGS and incubated with speciesspecific secondary antibodies conjugated with either AlexaFluor 488 or AlexFluor 594 for $2 \mathrm{~h}$ at room temperature. Some spinal sections perfused with $4 \%$ paraformaldehyde- $1 \%$ glutaraldehyde were treated with $1 \%$ sodium borohydride in PBS ( $\mathrm{pH} 7.4)$ for $20 \mathrm{~min}$ at room temperature to mitigate background fluorescence. These sections were treated with PBS-TGS as above, and incubated overnight at $4^{\circ} \mathrm{C}$ in PBS-TGS containing combinations of the following primary antibodies: anti-GABA (1:500, guinea pig, Chemicon, MA, USA), anti-glycine (1:300, rabbit, Chemicon), anti-vesicular inhibitory amino acid transporter (VIAAT; 1:200, rabbit, gift from Dr. Bruno Gasnier, INSERM, Strasbourg-Cedex, France), and anti-synaptobrevin (1:1000, mouse, Synaptic Systems, Gottingen, Germany). Sections were washed $3 \times 10 \mathrm{~min}$ in cold PBS-TGS, incubated at room temperature for $1 \mathrm{~h}$ in secondary antibodies: anti-guinea pig Alexa Fluor 488, anti-rabbit Alexa Fluor 594, and anti-mouse Alexa Fluor 680. All fluorescently labeled sections were washed three times in PBS, mounted on lysine-coated slides, air-dried and coverslipped using Vectashield mounting media containing DAPI (Vector Lab, CA, USA).

\section{MICROSCOPE AND IMAGE CAPTURING}

The majority of fluorescent sections were visualized with an Olympus fluorescent microscope. Images were acquired with a color CCD camera and ImagePro plus software (Media cybernetics Inc., Silver Spring, MD, USA) on an Apple Macintosh computer. Glutaraldehyde-treated, double- and triple-labeled sections were imaged on a Carl Zeiss LSM 510 confocal microscopy setup. An Axiovert 100M microscope with a motorized stage was operated using a PC running Zeiss LSM software version 3.2. Fluorescence was excited using Argon (514 nm) and $\mathrm{HeNe}(543,633 \mathrm{~nm})$ lasers (Lasos Lasertechnik; Jena, Germany). Images stacks were acquired with $10 \times$ dry and $40 \times$ oil immersion magnification ( 4 and 43 optical slices, respectively), and flattened into planar images. Adobe Photoshop was used as a digital layout tool for composition and overlay of acquired images.

\section{STEREOLOGICAL ANALYSIS}

For the estimation of GABAergic and NeuN positive profiles within the transplant area in QUIS-injected animals, serial immunostained sections of lumbar spinal cord were analyzed with Neurolucida (MicroBrightField Inc., Williston, VT, USA). The transplant site was identified under $20 \times$ magnifications. Cells were counted within $0.015 \mathrm{~mm}^{2}$ frame positioned over the transplant area at $60 \times$ magnification. Stereological estimation was performed in 25-30 sections/spinal cord. Results are presented at average \pm SEM.

\section{STATISTICAL ANALYSIS}

To analyze the overgrooming area of animals transplanted with control fibroblast cells and GABAergic precursor cells, the data were analyzed by two-way ANOVA with repetitive measurements with group and time post-transplantation as variables followed by Holm-Sidak post hoc analysis; level of significance was $p<0.05$.

\section{RESULTS}

Approximately $30 \%$ of animals that received quisqualic acid lesion in the spinal cord but did not display overgrooming behavior within two weeks post injury were discarded from the study. In general, overgrooming behavior was confined to ipsilateral at-level dermatomes, but a few animals displayed bilateral overgrooming behavior (Figure 1A).

\section{SPINAL CORD HISTOLOGY FOLLOWING QUIS LESION}

In the present experiment, micro-injections of $1.2 \mu \mathrm{l}$ of QUIS (total volume; $125 \mathrm{mM}$ ) at a depth of $1 \mathrm{~mm}$ from the dorsal surface of the spinal cord (Figure 1B) was sufficient to eliminate ipsilateral spinal neurons at the neck of the dorsal horn from laminae III to V/VI (Figure 1C). The lesion caused collapse of the gray matter into a thin dorso-ventral neuropil. Most neurons in the superficial laminae I and II, however, were spared from the injury even 3 weeks after QUIS lesion and a large number of NeuN-immunoreactive (NeuN-IR) cells were observed with a minimal gray matter disruption as previously reported (Lee et al., 2008). In almost all cases, neuronal cell losses were confined only to the dorsal gray matter ipsilateral to lesion. In a few animals, there were cell losses in the ipsilateral ventral horn and to the contralateral gray matter due to the spread of QUIS across the central canal, and in some instances, small cavitations in the spinal cord were observed in the ipsilateral lesioned gray matter (Yezierski et al., 1993). These cases were minor and may have been due to the age/weight of animal or proximal to medial placement of the glass pipette tip at the time of QUIS lesion.

\section{CHANGES IN GABA, GLYCINE, AND VIAAT FOLLOWING OUIS LESION}

Two weeks after QUIS lesion, there appeared substantially fewer number of endogenous GABA-IR in the superficial laminae I and II (Figure 2B) as described previously (Lee et al., 2008). Such a loss was specific to spinal level within the QUIS injury, since endogenous GABA-IR in the contralateral side and spinal levels outside the QUIS lesion area were not affected (Figure 2A). Immunostaining for a broader panel of markers for inhibitory neuronal signaling machinery revealed additional injury-induced histological changes. The other major spinal cord inhibitory neurotransmitter, glycine, was decreased in injured gray matter and in spared superficial laminae (Figure 2D), but remained unchanged in the contralateral side (Figure 2C).

Immunostaining for synaptobrevin was used to mark synaptic vesicles in the spinal cord. Colocalization of synaptobrevin, GABA, and VIAAT was detected in spinal cord dorsal horns as white punctate staining (Figures 2E-F). Triple-labeled puncta 

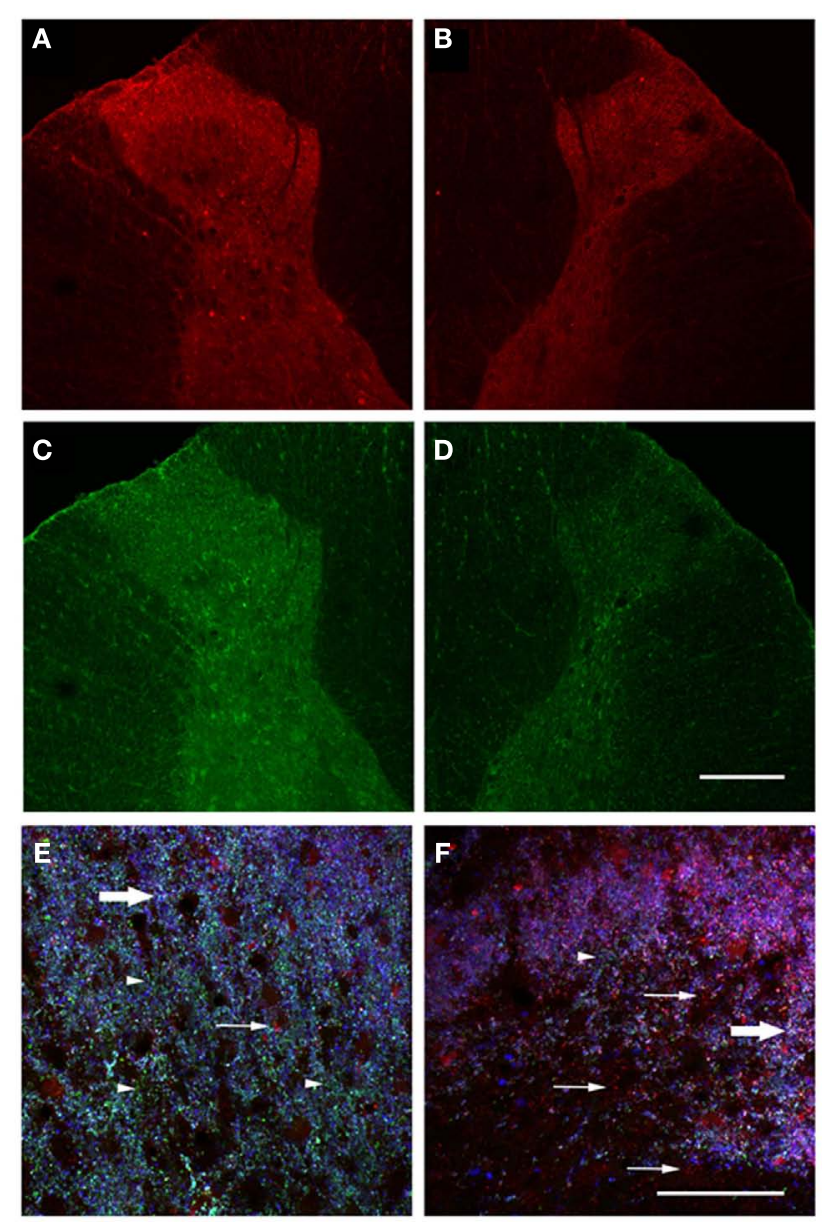

FIGURE 2 | Decreased immunoreactivity for inhibitory signaling components in injured spinal cord gray matter. Spinal cord sections were stained for GABA (A,B) and glycine (C,D). Uninjured dorsal horns showed robust staining for both neurotransmitters $(\mathbf{A}, \mathbf{C})$, but staining was decreased in injured dorsal horns (B,D). Spinal cord sections were also triple-stained for GABA, VIAAT, and synaptobrevin. A region within the uninjured dorsal horn was enlarged (E), showing extensive VIAAT labeling (arrowheads), few lone GABA puncta (arrows), and numerous triple-labeled white puncta (block arrows). Enlargement of injured dorsal horn (F) revealed substantially decreased VIAAT, abundant free GABA, and few triple-labeled puncta. Scale bars $=200 \mu \mathrm{m}$ (D); $50 \mu \mathrm{m}$ (F).

were abundant in dorsal horns contralateral to QUIS injection, particularly in superficial laminae (Figure 2E). QUIS-injected dorsal horns appear to exhibit reduced triple labeling of inhibitory synaptic vesicle markers (Figure 2F). The VIAAT-IR was abundant in gray matter contralateral to QUIS injection (Figure 2E) but substantially decreased in the ipsilateral dorsal horn after QUIS (Figure 2F) which suggest that inhibitory synaptic vesicles may be depleted in the injured dorsal horn.

\section{TIME COURSE OF CHANGES IN GABA IMMUNOREACTIVITY FROM ISOLATED EMBRYONIC CORTICAL PRECURSOR CELLS}

Under standard growth condition with constant $10 \mathrm{ng} / \mathrm{ml} \mathrm{FGF-}$ 2/N2 culture media, the proportion of GABA-IR cells found in freshly isolated primary cortical embryonic tissues was minimal (P0). Presence of low number of GABA-IR cells at this growth stage correlated with the in vitro GABA HPLC data (see below).

In order to promote and increase the proportion of cultured cortical precursor cells to differentiate in vitro into GABAergic phenotype, 5-10 days post-isolation neurospheres were exposed to $0.1 \mathrm{ng} / \mathrm{ml}$ (low), $1 \mathrm{ng} / \mathrm{ml}$ (mid), or $10 \mathrm{ng} / \mathrm{ml}$ (standard concentration) of FGF-2 for 4-16 h (Figure 3). GABA-IR cells were observed in all three conditions, and there were minimal difference between 4 and $16 \mathrm{~h}$ exposure in increasing the number of GABA-IR cells. Neurospheres exposed to $0.1 \mathrm{ng} / \mathrm{ml}$ FGF- 2 contained the highest number of mature-looking GABA-IR cells (Figures 3A,B,D). The inhibitory interneurons were mostly found inside neurospheres tightly packed as a cluster composed almost entirely of GABAIR cells. Individual GABA-IR neuron possessed small and large processes extending radially around and out from the neurosphere. Axonal bouton enlargements were observed in processes of some cells. Neurospheres exposed to 1 and $10 \mathrm{ng} / \mathrm{ml}$ FGF-2 did not contain as many GABA-IR cells within the neurospheres as the previous group. In these groups, most of the GABA-IR cells were observed outside the neurospheres, as a single cell, in a migratory pattern dispersing radially outward from the core of neurospheres. These cells possessed short bipolar or multipolar outgrowths from the soma (Figures 3C,D). The predifferentiated neurospheres contained numerous dividing cells indicated by presence of BrdU-IR (Figure 3E). At this stage none of GABA-IR NPCs colocalized with BrdU-IR, suggesting that these are pre-existing GABA cells.

\section{IN VITRO ANALYSIS OF FGF-2 PREDIFFERENTIATED NEUROSPHERES}

Several markers for mature and immature cell types were used to identify different phenotypes present in the predifferentiated neurospheres (Figure 4). A large proportion of NPCs expressed GAD65/67-IR where a subpopulation of them also expressed GABA-IR (Figure 4A). Many of GAD65/67-IR NPCs also colocalized with NeuN-IR (Figure 4B). Most of the embryonic progenitor cells labeled positive for nestin-IR irrespective of FGF-2 pre-differentiation conditions (Figure 4C). These NPCs possessed long elongated bipolar projections without any fine dendritic branches coming off from main projections. Large proportions of nestin-IR cells were positively double labeled with GABA (Figure 4C), but only a very small subset of GABA-IR NPCs positively colocalized with NeuN (Figure 4D), indicating presence of immature GABAergic NPCs in the neurospheres. BetaIII-tubulin-IR was observed in the NPCs, but only very small number of them coexpressed GABA-IR (Figure 4E). Many GABAIR NPCs colocalized with MAP-2, a marker for neural maturation (Figure 4F). GFAP-IR was almost not present in the neurospheres (data not shown).

\section{IN VITRO QUANTITATION OF GABA RELEASE FROM PREDIFFERENTIATED EMBRYONIC PRECURSOR CELLS}

The level of spontaneously released GABA concentration in the culture media was measured daily for 7 days using HPLC. Establishment of GABA release was critical to prove functional properties of our predifferentiated NPCs. The GABA concentrations from originally harvested (P0) and in vitro cultured (P1) neurospheres were measured. There were increased detectable levels 

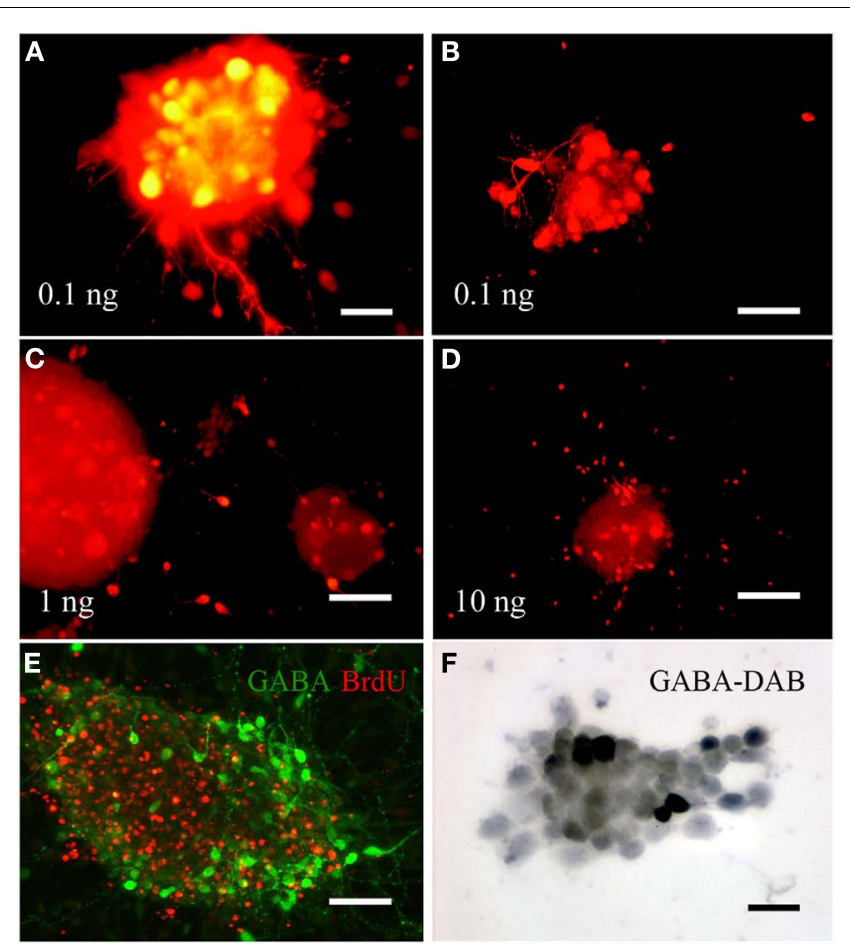

$F$

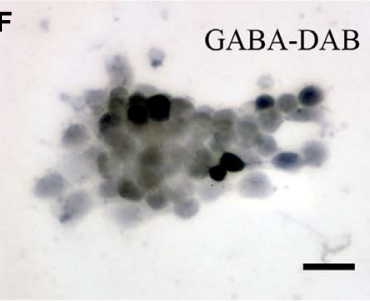

FIGURE 3 | Brief exposure to varying concentrations of FGF-2 induces differentiation of embryonic cortical progenitor cells into GABAergic phenotype in cultured neurospheres. Progenitor cells exposed to low concentration of FGF-2 expressed the largest number of GABA-IR cell $(\mathbf{A}, \mathbf{B})$. Majority of these cells were found in or adjacent to the neurospheres and did not show migratory pattern. Progenitor cells exposed to 1 or $10 \mathrm{ng} / \mathrm{ml} \mathrm{FGF-2} \mathrm{did} \mathrm{not} \mathrm{display} \mathrm{as} \mathrm{many} \mathrm{GABA-IR} \mathrm{cells} \mathrm{as} \mathrm{those} \mathrm{exposed} \mathrm{to}$ $0.1 \mathrm{ng} / \mathrm{ml}$. These GABA-IR cells were found predominantly outside the neurospheres radiating outwardly in a migratory pattern (C,D). Large proportion of NPCs can be labeled with BrdU, however, the GABA-IR cells did not co-label with BrdU (E). A high magnification light microscopy image of GABA-IR cells inside a neurosphere labeled with DAB peroxidase reaction (F). Scale bars $=20 \mu \mathrm{m}$ (A); $50 \mu \mathrm{m}$ (B-E).

of GABA present in the culture media starting from day luntil the last sample taken at day 7 post-isolation. For P0 cells, the GABA concentration in the media changed very little over time (Table 2). Majority of P0 neurospheres did not survive more than 4 days in vitro. The GABA concentrations from P0 cells at day 1 and day 4 were 0.3955 and $0.5609 \mu \mathrm{M} / 20 \mu \mathrm{l}$, respectively. On the other hand, there was a dramatic increase in GABA concentration present in the media of P1 neurospheres. Their initial GABA concentration was very low (day $1=0.0941 \mu \mathrm{M} / 20 \mu \mathrm{l}$ ) but increased by 10 -fold at day $7(1.0673 \mu \mathrm{M} / 20 \mu \mathrm{l})$ suggesting massive differentiation of NPCs into GABAergic cells.

\section{CHANGES IN OVERGROOMING AREA FOLLOWING TRANSPLANTATION OF GABAERGIC PRECURSOR CELLS}

Excitotoxic QUIS lesion caused a continuous and progressive damage to the spinal cord where the extent of the SCI as well as the size of peripheral overgrooming area increased progressively over time (Brewer and Yezierski, 1998). All of QUIS-lesioned animals that received transplantation of control cells (bovine
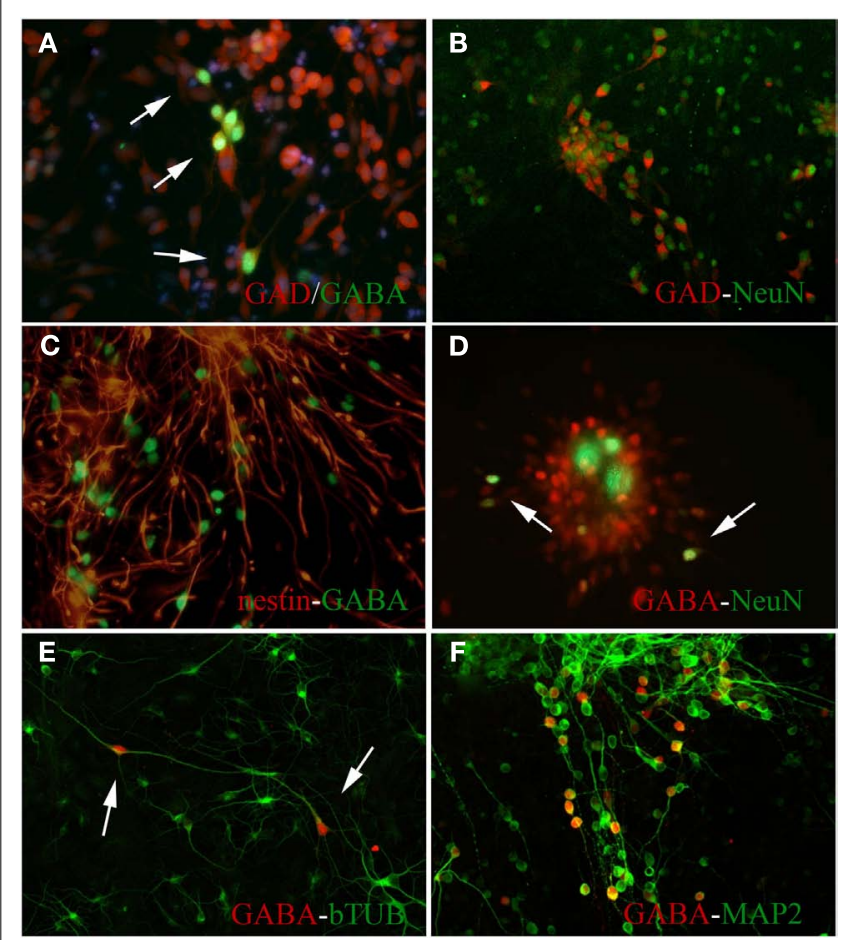

FIGURE 4 | Predifferentiated embryonic precursor neurospheres expressed robust immunoreactivity for GABA and other marker for cell differentiation 5-7 days after harvest. (A) Many of GABA-IR NPCs colocalized with GAD65/67-IR cells (arrows). (B) Majority of predifferentiated GAD65/67-IR NPCs also expressed NeuN-IR. (C) Majority of predifferentiated GABA-IR NPCs also expressed nestin-IR; Not every nestin-IR cells expressed GABA-IR. Many GABA-IR cells colocalized and expressed NeuN-IR (D), $\beta$-III-tubulin-IR (E), and MAP-2-IR (F).

adrenal fibroblast, $n=7$ ) showed a significant increase in overgrooming area over time where the area at pretransplantation (baseline) was $130.2 \pm 28.9 \mathrm{~mm}^{2}$ and increased by three folds to $348.1 \pm 115.08 \mathrm{~mm}^{2}$ at 1 week post-transplantation (Figures 5A,C and $\mathbf{6 A}$ ). By 2 and 3 weeks, the overgrooming area remained significantly enlarged to $438.5+121.0$ and $399.0+120.80 \mathrm{~mm}^{2}$, respectively $(p<0.05)$. On the other hand, QUIS-lesioned animals that received transplantation of predifferentiated GABA-IR NPCs $(n=27)$ did not show significant increase in overgrooming area, but remained at near baseline level during 3 weeks of the testing period (Figures 5B,D). In these rats, the baseline overgrooming area was $181.5+27.3 \mathrm{~mm}^{2}$, and 3 weeks after transplantation the overgrooming area remained at $237.3 \pm 55.8 \mathrm{~mm}^{2}$ (Figure 6A). Overall $55.6 \%$ of animals $(n=15 / 27)$ displayed overgrooming areas that were either the same or smaller than at pretransplantation stage; $27 \%$ of the animals $(n=7 / 27)$ displayed a $50 \%$ reduction in the overgrooming area by 3 weeks post-transplantation. Seven animals completely recovered from overgrooming injuries. When the percent changes in grooming areas were compared between groups, the overgrooming areas of rats that received GABA-IR NPCs were significantly smaller than fibroblast-transplanted control rats during the experimental period $(p<0.01$; Figure 6B). 


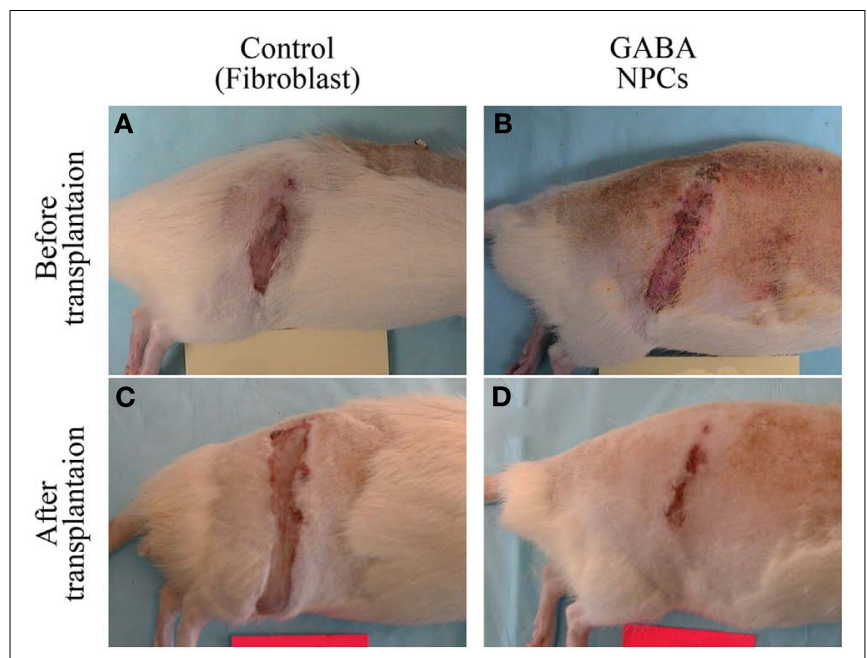

FIGURE 5 | Photomicrographs showing changes in size of overgrooming in QUIS animals transplanted with control bovine fibroblast cells [pretransplantation: (A) 3 weeks post: (C)] and predifferentiated GABA-IR NPCs [pretransplantation: (B), 3 weeks post: (D)].

\section{IDENTIFICATION OF GABA-IR NPCS IN THE SPINAL CORD OF OUIS-LESIONED ANIMALS}

Transplanted NPCs were observed within the spinal level of QUIS-lesioned sites. The immunohistochemical analysis revealed the NPCs were placed adjacent to the midline encompassing the medial aspect of spinal gray matter and the dorsal column (Figure 7). Surviving GABA-IR NPCs were observed covering a large extent of the dorsal horn from Rexed's lamina I-VI and as medial as the dorsal column. Based on our previous study (Furmanski et al., 2009), the grafted cells were distinguished from endogenous GABAergic interneurons by their different morphology and location in the spinal cord. Grafted NPCs appeared as large and round cells in superficial and deeper dorsal horn laminae in contrast to much smaller and elongated endogenous interneurons located mainly in superficial laminae. Overall, the spinal cords could be divided into three groups: those containing (i) large, (ii) moderate, or (iii) minimal number of GABAIR NPCs in the dorsal gray matter. The number of surviving GABA-IR NPCs inversely correlated with the size of overgrooming area. Animals with large number of GABA-IR NPCs in the spinal cord displayed the smallest to no overgrooming lesion area. Animals containing medium to low number of GABA-IR NPCs displayed same or increased overgrooming area compared to pretransplantation state.

Overall, the spinal cords could be divided into three groups: those containing (i) large, (ii) moderate, or (iii) minimal number of GABA-IR NPCs in the dorsal gray matter. The number of surviving GABA-IR NPCs inversely correlated with the size of overgrooming area. Animals with large number of GABA-IR NPCs in the spinal cord displayed the smallest to no overgrooming lesion area. Animals containing medium to low number of GABA-IR NPCs displayed same or increased overgrooming area compared to pretransplantation state.

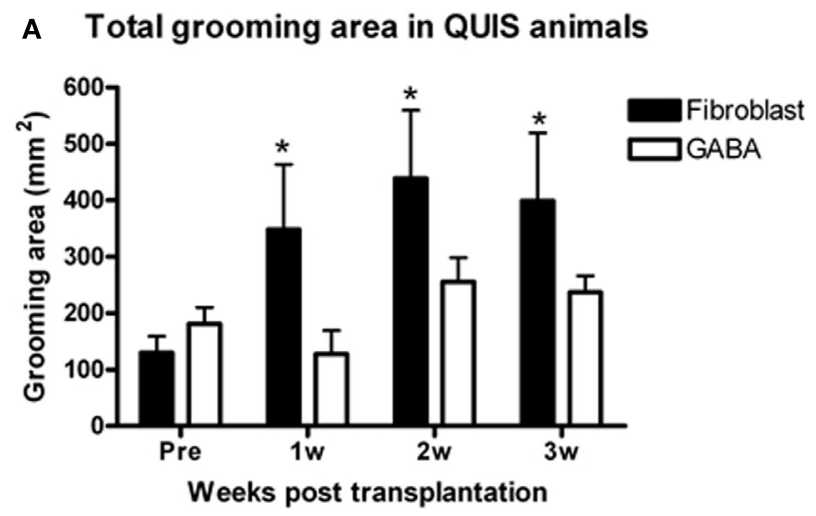

B

Grooming area

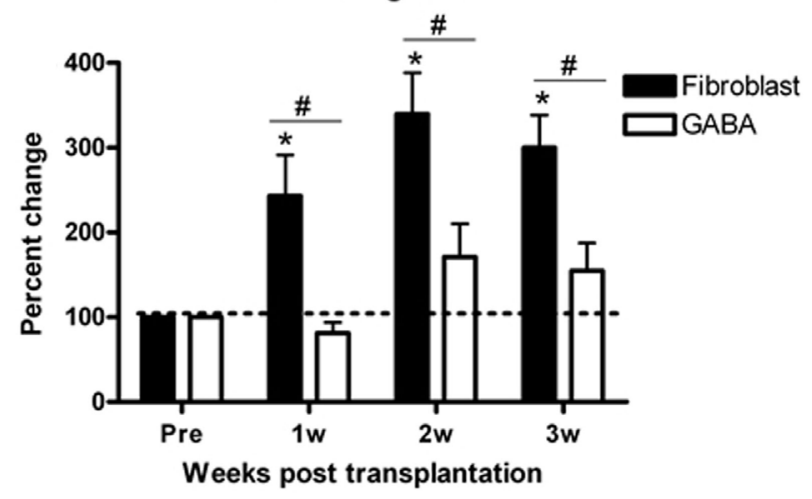

FIGURE 6 | Percent change of the overgrooming area from pretransplantation for GABA and fibroblast-transplanted rats. Control animals displayed significant increases in total overgrooming area $(\mathbf{A})$ and percent change of overgrooming area (B) post-transplantation vs. pretransplantation and also compared to GABA-transplanted animals. GABA-transplanted rats did not display statistically significant changes in either total or percent change of overgrooming compared to pretransplantation. ${ }^{*} p<0.05$ vs. pretransplantation, ${ }^{*} p<0.05$ vs. GABA group.

\section{IN VIVO DIFFERENTIATION OF EMBRYONIC GABA-IR NPCs}

Surviving NPCs within the injured spinal cord exhibited immunoreactivity for GABA and several other cell markers. The GABA-IR cells ranged in size of a small interneuron to a large spinal motor neuron (Figure 8 left two columns). The GABA-IR cells double labeled with neuronal marker, NeuN (Figures 8A-D), but did not express nestin-IR indicating differentiation into mature neurons. Although GFAP- and $\beta$-III-tubulin-IR were present within the transplantation site of NPCs, neither of them colocalized with GABA-IR (Figures 8I-P).

\section{STEREOLOGICAL OUANTITATION OF GABA-IR CELLS IN THE OUIS SPINAL CORD}

Stereological evaluation was performed on spinal cord sections from these animals in a tissue volume of $0.7 \pm 0.04 \mathrm{~mm}^{3}$. About $30-40 \%$ of surviving predifferentiated GABA-IR cells colocalized with NeuN indicating maturity to neuronal phenotype (Table 1). The majority of GABA-IR cells $(67.8 \pm 2.7 \%)$ within the 

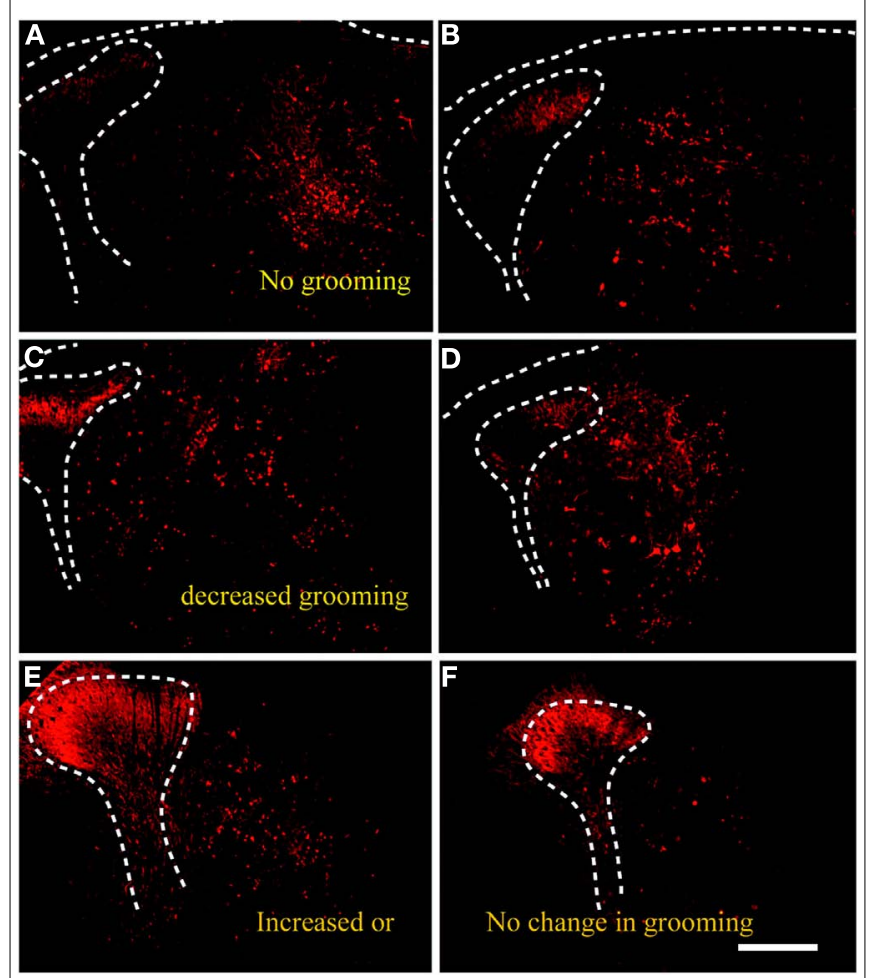

FIGURE 7 | Transplanted predifferentiated GABA-IR NPCs were visible in the spinal cord of QUIS animals three weeks after transplantation, and showed varying densities in the host spinal cord. Animals that stopped overgrooming [healed; $(\mathbf{A}, \mathbf{B})$ ] or displayed reduction in overgrooming $\mathbf{( C , D )}$ exhibited large number of transplanted GABA-IR NPCs in the spinal gray matter. Animals that continued to groom contained very few number of surviving GABA-IR cells in the spinal cord (E,F). Scale bars $=500 \mu \mathrm{m}$.

transplant area did not colocalize with NeuN indicating immaturity 3 weeks post-transplantation into host spinal cord. Similar numbers were obtained when sections were processed for GAD65/67 (data not shown).

\section{DISCUSSION}

Results from the present study show that intraspinal transplantation of predifferentiated embryonic GABAergic NPCs, but not bovine fibroblast cells, significantly decreases self-injurious overgrooming lesions observed in QUIS injured rats. The decrease in overgrooming may be mediated by the GABA released from the transplanted precursor cells since the reduction in grooming was observed primarily GABA-transplated QUIS animals. Manifestation of overgrooming behavior is thought to have a relation with dysesthetic and nociceptive sensations since subdural transplantation of analgesic compound-releasing chromaffin cells can reverse mechanical and thermal nociceptive thresholds in QUIS rats, in addition to significant reduction on the size of overgrooming area by 2 weeks post-transplantation compared to muscle transplanted control rats (Brewer and Yezierski, 1998).

In our experiment, reversal of overgrooming lesion was observed in 55.6\% $(n=15 / 27)$ of GABA-transplanted rats from which seven rats recovered completely from self-inflicted dermal injuries 3 weeks post-transplantation. The main contributing factor for these recoveries may be the secretion of GABA in the lesioned dorsal horn by the embryonic GABA-IR NPCs transplanted into the host spinal cord, since fibroblast-transplanted control rats $(n=7)$ or QUIS animals with only a small number of surviving transplanted GABA cells did not show a decrease in their overgrooming lesion. In fact, the latter group of animals showed increasing overgrooming lesion size overtime closely resembling the pattern observed in fibroblast-transplanted control rats. The results from our experiment show intraspinal transplantation of GABA secreting embryonic precursor cells are effective in reducing centrally- and peripherally mediated nociceptive behaviors without causing sensory and motor deficits, similar to observations reported by others (Hendricks et al., 2006; Mukhida et al., 2007; Wolfe et al., 2007).

Changes in the number and expression of endogenous GABA leading to abnormal inhibitory signaling following spinal or peripheral nerve injuries have been well documented in several rodents pain models, yet their role in expression of nociceptive behaviors remain divided (Polgar et al., 2003; Lee et al., 2008; Polgar and Todd, 2008; Meisner et al., 2010). The postulated loss of GABAergic neurons is controversial, however, as a reduction in GABAergic immunoreactivity in parallel with the development of neuropathic pain symptoms is not always observed (Polgar et al., 2003, 2004; Polgar and Todd, 2008). Nevertheless, alternative explanations for disinhibition after nerve injury include reduced GABA synthesis in existing intact, but dysfunctional neurons or reduced excitatory drive to GABAergic dorsal horn neurons following loss of primary afferent input to these cells. Alterations in GABA receptors, e.g., loss of receptors or reversion to a neonatal excitatory and pronociceptive GABA phenotype may also occur. Diminished GABAergic inhibitory effects via reduced expression of the potassium co-transporter KCC-2 and disruption of the chloride gradient has been suggested as an underlying mechanism of activated microglia in neuropathic pain induction (Coull et al., 2003, 2005). However, pharmacologic findings argue against a complete excitatory reversion since GABA and GABAergic agonists can reduce neuropathic pain behaviors. In addition, electrophysiological studies suggest that diminished GABA release, rather than changes in receptor density, account for the loss in GABAergic inhibition in peripheral nerve injury models (Moore et al., 2002). Regardless whether or not overt GABAergic cellular death occurs, it is clear that loss of spinal inhibitory tone and consequent abnormal hyperexcitability contribute to the maintenance of neuropathic pain, and is a promising target for intervention.

Previously, our group reported selective loss of endogenous GABA-IR cells following excitotoxic QUIS lesion in rats (Lee et al., 2008), similar to the previously mentioned animal pain/nociceptive models that reported loss of GABAergic cells. It is not clear whether the decrease of GABA-labeled cells is due to apoptosis, down-regulation of GAD genes, or another mechanism. Spinal contusion injury-induced secretion of excitatory amino acids and subsequent activation of metabotropic glutamate receptors (mGluRs) has been shown to increase the GABA concentration in the spinal cord by $160 \%(4.8 \mu \mathrm{M})$ within half an hour of injury (Mills et al., 2001). Blocking mGluR1/5 with antagonist agents (10 nM AIDA, LY 367385 + MPEP) can prevent GABA release. It is possible that excessive mGluR1/5 activity after SCI 

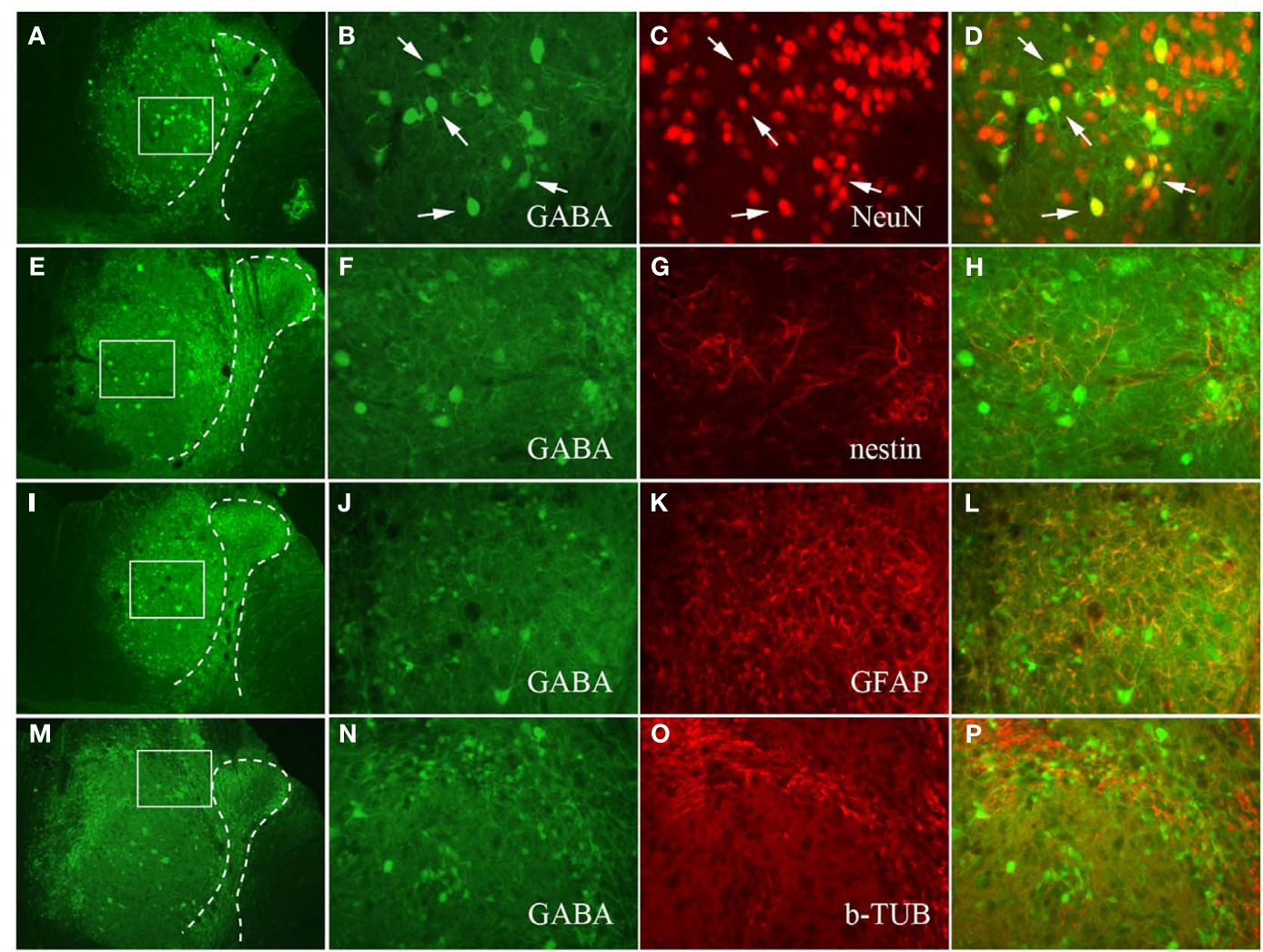

FIGURE 8 | Photomicrographs of QUIS spinal cord transplanted with GABA-IR NPCs. The NPCs were double labeled with NeuN (A-D), nestin (E-H), GFAP (I-L), and $\beta$-III-tubulin (M-P). Medium (A,E,I,M) and high magnification (B,F,J,N) of QUIS spinal cord stained for GABA-IR NPCs. The dotted lines represent the spinal gray matter, and white boxes represent the $\mathrm{ROI}$ in panels $\mathbf{( B , F , J , N ) . ~ M a j o r i t y ~ o f ~ G A B A - I R ~ N P C s ~ d o u b l e ~ l a b e l e d ~ w i t h ~}$ NeuN-IR (B-D). However, the GABA-IR NPCs did not colocalize with nestin (F-H), GFAP (J-L), or with $\beta$-III-tubulin (N-P).

Table 1 | Stereological quantitation of predifferentiated GABAergic precursor cells following intraspinal transplantation of QUIS animals.

\begin{tabular}{|c|c|c|c|c|c|c|c|}
\hline ID & $\begin{array}{l}\text { GABA only } \\
\text { (single) }\end{array}$ & $\begin{array}{l}\text { GABA + NeuN } \\
\text { (double) }\end{array}$ & GABA total & $\%$ of GABA only & $\%$ of GABA + NeuN & $\begin{array}{l}\text { Total counting } \\
\text { area }\left(\mu \mathbf{m}^{2}\right)\end{array}$ & Total volume $\left(\mathrm{mm}^{3}\right)$ \\
\hline Q12 & 606 & 401 & 1007 & 60 & 40 & 4350 & 0.74 \\
\hline Q16 & 952 & 422 & 1374 & 69 & 31 & 3600 & 0.61 \\
\hline Q24 & 314 & 137 & 451 & 70 & 30 & 3600 & 0.61 \\
\hline Q26 & 536 & 204 & 740 & 72 & 28 & 4350 & 0.74 \\
\hline
\end{tabular}

could contribute to depletion of cellular GABA stores, indicated by decreased GABA immunoreactivity. We also provide evidence that glycine is reduced similar to GABA in the injured dorsal horn. Since GABA and glycine are frequently co-released at synapses, in part due to the shared vesicular transporter VIAAT (Wojcik et al., 2006; Juge et al., 2009), excessive mGluR1/5 activity could contribute to depletion of glycine stores as well.

The VIAAT loads GABA and glycine into presynaptic vesicles at inhibitory synapses (Dumoulin et al., 1999). In the current experiments, we found that VIAAT-IR was decreased in the QUIS-lesioned dorsal horn. Furthermore, colocalization of GABA, VIAAT, and the synaptic protein synaptobrevin was substantially decreased in the injured dorsal horn. An injury-induced decrease in VIAAT expression could lead to an inability to load available GABA into presynaptic vesicles, which could be reflected by increased free GABA-IR in the injured dorsal horn. Another possible mechanism is that QUIS-induced cell death in the dorsal horn deprives inhibitory neurons of their targets, causing axonal retraction, and decreased axonal trafficking of inhibitory vesicles. Alone or in combination, these potential causes of decreased inhibitory synaptic communication could operate in concert with previously described mechanisms of spinal cord hyperexcitability that are associated with injury-induced chronic pain.

Embryonic stem and precursor cells can be grown in culture and, depending on growth factors, can be induced to differentiate into many different cell types. In this study, we explored ways to promote and increase the number of cultured cortical precursor cells to differentiate in vitro into GABAergic phenotype by varying 
Table 2 | Non-stimulation-induced released GABA concentration in the N2 growth media over time for P0 and P1 embryonic precursor cells $(\mu \mathrm{M} / 20 \mu \mathrm{I})$.

\begin{tabular}{lllllll}
\hline & Day 1 & Day 2 & Day 3 & Day 4 & Day 5 & Day 6 \\
\hline Passage 0 & 0.3955 & 0.3187 & 0.3844 & 0.5609 & N/A & N/A \\
Passage 1 & 0.0941 & 0.0993 & 0.1540 & 0.2088 & 0.6500 & N/A \\
\hline
\end{tabular}

the concentration level of FGF-2 present in the growth media. Cells grown under standard concentration of FGF-2 then switched to low concentration $(0.1 \mathrm{ng} / \mathrm{ml})$ for several hours facilitated transformation to GABAergic phenotype. The molecular biochemistry underlying such transformation remains unclear. It is important to note that not all phenotypic GABA cells colocalized with the neuronal marker NeuN. The vast majority of GABAergic cells colocalized with $\beta$-III-tubulin and MAP-2 suggesting incomplete neuronal differentiation 24-36 h after FGF-2 removal.

In addition to GABA, the vast majority of NPCs in these cultures were nestin-IR, indicating they were undifferentiated progenitor cells. All GABA-positive cells were double labeled with nestin. But no GABA cells colocalized with GFAP-IR cells indicating that most of our GABA cells were still in immature state and GABA was not present in the astrocytes. The majority of GABA cells were found as a cluster inside the neurospheres, suggesting they are clonally derived. Functional biochemical properties of our GABAergic neurospheres were demonstrated by high-pressure liquid chromatography (HPLC) where the secreted/released concentration of GABA in the culture media increased 10-fold to $1 \mu \mathrm{M} / 20 \mu \mathrm{l}$ culture media over a 7-day period in vitro (Table 2 ). We were not able to obtain in vitro GABA HPLC data for P0 cells beyond 4 days due to decreased representation of GABA neurons in the culture with time (data not shown). Only the P0 precursor cells proliferate in the $\mathrm{N} 2$ culture media while the P0 GABA cells do not. Therefore in the non-proliferating P0 GABA cells that are already differentiated cells become a negligible fraction by day 4. In contrast the large numbers of P1 precursors differentiate into GABAergic cells persist longer in the culture in the absence of any cell proliferation. These data demonstrate that brief exposure of embryonic cortical precursor cells to low concentration of FGF-2 stimulates GABAergic cell differentiation, but that the differentiation status remains largely incomplete.

Overgrooming behavior observed in QUIS rats is thought to have a nociceptive component in its expression. Previously, subdural transplantation of chromaffin cells in the spinal cord of QUIS animals significantly decreased their overgrooming area directly demonstrating analgesic compound secreted from chromaffin cells, mainly norepinephrine, can reduce the overgrooming behavior (Brewer and Yezierski, 1998). In the present experiment, intraspinal transplantation of predifferentiated embryonic GABAergic cells also significantly decreased the overgrooming area at all-time points studied compared to fibroblast-transplanted

\section{REFERENCES}

Azkue, J. J., Zimmermann, M., Hsieh, T. F., and Herdegen, T. (1998). Peripheral nerve insult induces NMDA receptor-mediated, delayed degeneration in spinal neurons. Eur. J. Neurosci. 10, 2204-2206.

Bethea, J. R., Castro, M., Keane, R. W., Lee, T. T., Dietrich, W. D., and Yezierski, R. P. (1998). Traumatic spinal cord injury induces nuclear

control QUIS rats. The main factor for such an effect was most likely the absence of GABA cells since QUIS animals with very few surviving GABA cells also showed increased overgrooming. We know from past reports that only about 5-10\% of transplants survive following incorporation to the host CNS (Chow et al., 2000; Cao et al., 2002; Hendricks et al., 2006; Lepore et al., 2006) but this number is sufficient for producing a significant effect on host behavior. Our recent paper (Jergova et al., 2012) shows that intraspinal injection of GABAergic progenitors partially restore inhibitory tone in the spinal cord in CCI model. Behavioral and electrophysiological experiments showed that the analgesic effect of grafted cell is positively or negatively modulated by GABA reuptake inhibitor or GABA receptor antagonist respectively.

In present study, quantitation of surviving GABAergic cells from select tissues showed that over $67 \%$ of transplanted cells remained as incompletely differentiated GABAergic cells. However, about $40 \%$ of predifferentiated cells displayed neuronal phenotypes positive for NeuN immunoreactivity.

Several reports exist that describe transplantations of predifferentiated GABAergic and non-GABAergic embryonic precursor cells to alleviate peripheral and central neuropathic pain (Eaton et al., 1999b; Stubley et al., 2001; Hendricks et al., 2006; Mukhida et al., 2007; Jergova et al., 2012). However, the present study is first to describe the effect of predifferentiated embryonic GABAergic cells transplanted in SCI animals to reverse dysesthetic/nociceptive behaviors.

In summary, the current study suggests transplantation of predifferentiated embryonic GABAergic cells in QUIS-lesioned rats can greatly reduce the overgrooming lesion size. Such reduction may be mediated with the release of GABA from the transplants. GABA replacement therapy through cell transplantation could be used to offset losses of inhibitory signaling molecules in injured spinal cord gray matter. The reversal of overgrooming behavior was associated with the density of surviving GABA-IR transplants in the injured host spinal cord.

\section{ACKNOWLEDGMENTS}

The authors would like to thank Drs. Robert Yezierski, ChenGuang Yu, and Shi-Bing Chen for assistance with quisqualic acid surgeries. The authors would also like to thank Ms. Sayuri Rendon, Linda Daniels, and Drs. Ivette Felipe and Maria Collado for their help with immunohistochemistry. This work was supported by NS51667, and a Lois Pope LIFE Fellowship to Jeung Woon Lee.

factor-kappaB activation. J. Neurosci. 18, 3251-3260.

Brewer, K. L., Lee, J. W., Downs, H., Oaklander, A. L., and Yezierski, R. P. (2008). Dermatomal scratching after intramedullary quisqualate injection: correlation with cutaneous denervation. J. Pain 9, 999-1005.

Brewer, K. L., and Nolan, T. A. (2007). Spinal and supraspinal changes in tumor necrosis factor-alpha 
expression following excitotoxic spinal cord injury. J. Mol. Neurosci. 31, 13-21.

Brewer, K. L., and Yezierski, R. P. (1998). Effects of adrenal medullary transplants on pain-related behaviors following excitotoxic spinal cord injury. Brain Res. 798, 83-92.

Bruce, J. C., Oatway, M. A., and Weaver, L. C. (2002). Chronic pain after clipcompression injury of the rat spinal cord. Exp. Neurol. 178, 33-48.

Cao, Q. L., Howard, R. M., Dennison, J. B., and Whittemore, S. R. (2002). Differentiation of engrafted neuronal-restricted precursor cells is inhibited in the traumatically injured spinal cord. Exp. Neurol. 177, 349-359.

Carlton, S. M., Du, J., Tan, H. Y., Nesic, O., Hargett, G. L., Bopp, A. C., Yamani, A., Lin, Q., Willis, W. D., and Hulsebosch, C. E. (2009). Peripheral and central sensitization in remote spinal cord regions contribute to central neuropathic pain after spinal cord injury. Pain 147, 265-276.

Chow, S. Y., Moul, J., Tobias, C. A., Himes, B. T., Liu, Y., Obrocka, M., Hodge, L., Tessler, A., and Fischer, I. (2000). Characterization and intraspinal grafting of EGF/bFGF-dependent neurospheres derived from embryonic rat spinal cord. Brain Res. 874, 87-106.

Cizkova, D., Kakinohana, O., Kucharova, K., Marsala, S., Johe, K., Hazel, T., Hefferan, M. P., and Marsala, M. (2007). Functional recovery in rats with ischemic paraplegia after spinal grafting of human spinal stem cells. Neuroscience 147, 546-560.

Coggeshall, R. E., Lekan, H. A., White, F. A., and Woolf, C. J. (2001). A-fiber sensory input induces neuronal cell death in the dorsal horn of the adult rat spinal cord. J. Comp. Neurol. 435, 276-282.

Coull, J. A., Beggs, S., Boudreau, D., Boivin, D., Tsuda, M., Inoue, K., Gravel, C., Salter, M. W., and De Koninck, Y. (2005). BDNF from microglia causes the shift in neuronal anion gradient underlying neuropathic pain. Nature 438, 1017-1021.

Coull, J. A., Boudreau, D., Bachand, K., Prescott, S. A., Nault, F., Sik, A., De Koninck, P., and De Koninck, Y. (2003). Trans-synaptic shift in anion gradient in spinal lamina I neurons as a mechanism of neuropathic pain. Nature 424, 938-942.

Dumoulin, A., Rostaing, P., Bedet, C., Levi, S., Isambert, M. F., Henry, J. P., Triller, A., and Gasnier, B. (1999). Presence of the vesicular inhibitory amino acid transporter in GABAergic and glycinergic synaptic terminal boutons. J. Cell. Sci. 112(Pt 6), 811-823.

Eaton, M. J., Martinez, M. A., and Karmally, S. (1999a). A single intrathecal injection of GABA permanently reverses neuropathic pain after nerve injury. Brain Res. 835, 334-339.

Eaton, M. J., Plunkett, J. A., Martinez, M. A., Lopez, T., Karmally, S., Cejas, P., and Whittemore, S. R. (1999b). Transplants of neuronal cells bioengineered to synthesize GABA alleviate chronic neuropathic pain. Cell Transplant. 8, 87-101.

Edwards, L., Nashmi, R., Jones, O., Backx, P., Ackerley, C., Becker, L., and Fehlings, M. G. (2002). Upregulation of $\mathrm{Kv} 1.4$ protein and gene expression after chronic spinal cord injury. J. Comp. Neurol. 443, 154-167.

Finnerup, N. B., and Jensen, T. S. (2004). Spinal cord injury pain - mechanisms and treatment. Eur. J. Neurol. 11, 73-82.

Finnerup, N. B., Sindrup, S. H., Bach, F. W., Johannesen, I. L., and Jensen, T. S. (2002). Lamotrigine in spinal cord injury pain: a randomized controlled trial. Pain 96, 375-383.

Furmanski, O., Gajavelli, S., Lee, J. W., Collado, M. E., Jergova, S., and Sagen, J. (2009). Combined extrinsic and intrinsic manipulations exert complementary neuronal enrichment in embryonic rat neural precursor cultures: an in vitro and in vivo analysis. J. Comp. Neurol. 515, 56-71.

Gorman, A. L., Yu, C. G., Ruenes, G. R., Daniels, L., and Yezierski, R. P. (2001). Conditions affecting the onset, severity, and progression of a spontaneous pain-like behavior after excitotoxic spinal cord injury. J. Pain 2, 229-240.

Hains, B. C., Klein, J. P., Saab, C. Y., Craner, M. J., Black, J. A., and Waxman, S. G. (2003a). Upregulation of sodium channel Nav1.3 and functional involvement in neuronal hyperexcitability associated with central neuropathic pain after spinal cord injury. J. Neurosci. 23, 8881-8892.

Hains, B. C., Willis, W. D., and Hulsebosch, C. E. (2003b). Temporal plasticity of dorsal horn somatosensory neurons after acute and chronic spinal cord hemisection in rat. Brain Res. 970, 238-241.

Hama, A. T., and Sagen, J. (1993). Reduced pain-related behavior by adrenal medullary transplants in rats with experimental painful peripheral neuropathy. Pain 52, 223-231.
Hendricks, W. A., Pak, E. S., Owensby, J. P., Menta, K. J., Glazova, M., Moretto, J., Hollis, S., Brewer, K. L., and Murashov, A. K. (2006). Predifferentiated embryonic stem cells prevent chronic pain behaviors and restore sensory function following spinal cord injury in mice. Mol. Med. $12,34-46$

Hoheisel, U., Scheifer, C., Trudrung, P. Unger, T., and Mense, S. (2003). Pathophysiological activity in rat dorsal horn neurones in segments rostral to a chronic spinal cord injury. Brain Res. 974, 134-145.

Hwang, J. H., and Yaksh, T. L. (1997). The effect of spinal GABA receptor agonists on tactile allodynia in a surgically-induced neuropathic pain model in the rat. Pain 70, 15-22.

Ibuki, T., Hama, A. T., Wang, X. T., Pappas, G. D., and Sagen, J. (1997). Loss of GABA-immunoreactivity in the spinal dorsal horn of rats with peripheral nerve injury and promotion of recovery by adrenal medullary grafts. Neuroscience 76, 845-858.

Jergova, S., Hentall, I. D., Gajavelli, S., Varghese, M. S., and Sagen, J. (2012). Intraspinal transplantation of GABAergic neural progenitors attenuates neuropathic pain in rats: a pharmacologic and neurophysiological evaluation. Exp. Neurol. 234, 39-49.

Juge, N., Muroyama, A., Hiasa, M. Omote, H., and Moriyama, Y. (2009). Vesicular inhibitory amino acid transporter is a Cl-/gammaaminobutyrate Co-transporter. J. Biol. Chem. 284, 35073-35078.

Kim, D. S., Jung, S. J., Nam, T. S., Jeon, Y. H., Lee, D. R., Lee, J. S., Leem, J. W., and Kim, D. W. (2010). Transplantation of GABAergic neurons from ESCs attenuates tactile hypersensitivity following spinal cord injury. Stem Cells 28, 2099-2108.

Kwon, B. K., Stammers, A. M., Belanger, L. M., Bernardo, A., Chan, D., Bishop, C. M., Slobogean, G. P., Zhang, H., Umedaly, H., Giffin, M., Street, J., Boyd, M. C., Paquette, S. J., Fisher, C. G., and Dvorak, M. F. (2010). Cerebrospinal fluid inflammatory cytokines and biomarkers of injury severity in acute human spinal cord injury. J. Neurotrauma 27, 669-682.

Lee, J. W., Furmanski, O., Castellanos, D. A., Daniels, L. A., Hama, A. T., and Sagen, J. (2008). Prolonged nociceptive responses to hind paw formalin injection in rats with a spinal cord injury. Neurosci. Lett. 439, 212-215.
Lee, J. W., Yezierski, R. P., and Sagen, J. (2001). Transplantation of embryonic progenitor cells into excitotoxically lesioned adult spinal cord: in vivo survival and differentiation in quisqualic acid-treated spinal cord. Soc. Neurosci. 27, abstr. 369.6.

Lepore, A. C., Neuhuber, B., Connors, T. M., Han, S. S., Liu, Y., Daniels, M. P., Rao, M. S., and Fischer, I. (2006). Long-term fate of neural precursor cells following transplantation into developing and adult CNS. Neuroscience 142, 287-304.

Malan, T. P., Mata, H. P., and Porreca, F. (2002). Spinal GABA(A) and GABA(B) receptor pharmacology in a rat model of neuropathic pain. Anesthesiology 96, 1161-1167.

Mann, C. M., Lee, J. H., Hillyer, J., Stammers, A. M., Tetzlaff, W., and Kwon, B. K. (2010). Lack of robust neurologic benefits with simvastatin or atorvastatin treatment after acute thoracic spinal cord contusion injury. Exp. Neurol. 221, 285-295.

Marsala, M., Kakinohana, O., Yaksh, T. L., Tomori, Z., Marsala, S., and Cizkova, D. (2004). Spinal implantation of hNT neurons and neuronal precursors: graft survival and functional effects in rats with ischemic spastic paraplegia. Eur. J. Neurosci. 20, 2401-2414.

Meisner, J. G., Marsh, A. D., and Marsh, D. R. (2010). Loss of GABAergic interneurons in laminae I-III of the spinal cord dorsal horn contributes to reduced GABAergic tone and neuropathic pain after spinal cord injury. J. Neurotrauma 27, 729-737.

Mills, C. D., Xu, G. Y., Mcadoo, D. J., and Hulsebosch, C. E. (2001). Involvement of metabotropic glutamate receptors in excitatory amino acid and GABA release following spinal cord injury in rat. J. $\mathrm{Neu}$ rochem. 79, 835-848.

Miranda, J. D., White, L. A., Marcillo, A. E., Willson, C. A., Jagid, J., and Whittemore, S. R. (1999). Induction of Eph B3 after spinal cord injury. Exp. Neurol. 156, 218-222.

Moore, K. A., Kohno, T., Karchewski, L. A., Scholz, J., Baba, H., and Woolf, C. J. (2002). Partial peripheral nerve injury promotes a selective loss of GABAergic inhibition in the superficial dorsal horn of the spinal cord. J. Neurosci. 22, 6724-6731.

Mukhida, K., Mendez, I., Mcleod, M., Kobayashi, N., Haughn, C., Milne, B., Baghbaderani, B., Sen, A., Behie, L. A., and Hong, M. (2007). Spinal GABAergic transplants attenuate mechanical allodynia in a rat model of neuropathic pain. Stem Cells 25, 2874-2885. 
Nashmi, R., and Fehlings, M. G. (2001). Mechanisms of axonal dysfunction after spinal cord injury: with an emphasis on the role of voltagegated potassium channels. Brain Res. Brain Res. Rev. 38, 165-191.

O’Brien, M. F., Lenke, L. G., Lou, J., Bridwell, K. H., and Joyce, M. E. (1994). Astrocyte response and transforming growth factor-beta localization in acute spinal cord injury. Spine 19, 2321-2329; discussion 2330.

Polgar, E., Gray, S., Riddell, J. S., and Todd, A. J. (2004). Lack of evidence for significant neuronal loss in laminae I-III of the spinal dorsal horn of the rat in the chronic constriction injury model. Pain 111, 144-150.

Polgar, E., Hughes, D. I., Riddell, J. S., Maxwell, D. J., Puskar, Z., and Todd, A. J. (2003). Selective loss of spinal GABAergic or glycinergic neurons is not necessary for development of thermal hyperalgesia in the chronic constriction injury model of neuropathic pain. Pain 104, 229-239.

Polgar, E., and Todd, A. J. (2008). Tactile allodynia can occur in the spared nerve injury model in the rat without selective loss of GABA or $\mathrm{GABA}(\mathrm{A})$ receptors from synapses in laminae I-II of the ipsilateral spinal dorsal horn. Neuroscience 156, 193-202.

Saito, N., Yamamoto, T., Watanabe, T., Abe, Y., and Kumagai, T. (2000). Implications of $\mathrm{p} 53$ protein expression in experimental spinal cord injury. J. Neurotrauma 17, 173-182.

Scholz, J., Broom, D. C., Youn, D. H., Mills, C. D., Kohno, T., Suter, M. R., Moore, K. A., Decosterd, I., Coggeshall, R. E., and Woolf, C. J. (2005). Blocking caspase activity prevents transsynaptic neuronal apoptosis and the loss of inhibition in lamina II of the dorsal horn after peripheral nerve injury. J. Neurosci. $25,7317-7323$.

Siddall, P. J. (2009). Management of neuropathic pain following spinal cord injury: now and in the future. Spinal Cord 47, 352-359.

Sokal, D. M., and Chapman, V. (2003). Effects of spinal administration of muscimol on C- and A-fibre evoked neuronal responses of spinal dorsal horn neurones in control and nerve injured rats. Brain Res. 962, 213-220.

Springer, J. E., Azbill, R. D., and Knapp, P. E. (1999). Activation of the caspase-3 apoptotic cascade in traumatic spinal cord injury. Nat. Med. 5, 943-946.

Stubley, L. A., Martinez, M. A., Karmally, S., Lopez, T., Cejas, P., and Eaton, M. J. (2001). Only early intervention with gamma-aminobutyric acid cell therapy is able to reverse neuropathic pain after partial nerve injury. J. Neurotrauma 18, 471-477.

Sugimoto, T., Bennett, G. J., and Kajander, K. C. (1990). Transsynaptic degeneration in the superficial dorsal horn after sciatic nerve injury: effects of a chronic constriction injury, transection, and strychnine. Pain 42, 205-213.

Sugimoto, T., Takemura, M., Sakai, A., and Ishimaru, M. (1987). Rapid transneuronal destruction following peripheral nerve transection in the medullary dorsal horn is enhanced by strychnine, picrotoxin and bicuculline. Pain 30, 385-393.

Vaysse, L., Sol, J. C., Lazorthes, Y., Courtade-Saidi, M., Eaton, M. J., and Jozan, S. (2011). GABAergic pathway in a rat model of chronic neuropathic pain: modulation after intrathecal transplantation of a human neuronal cell line. Neurosci. Res. 69, 111-120.

Watanabe, K., Nakamura, M., Iwanami, A., Fujita, Y., Kanemura, Y., Toyama, Y., and Okano, H. (2004). Comparison between fetal spinal-cordand forebrain-derived neural stem/progenitor cells as a source of transplantation for spinal cord injury. Dev. Neurosci. 26, 275-287.
Whiteside, G. T., and Munglani, R. (2001). Cell death in the superficial dorsal horn in a model of neuropathic pain. J. Neurosci. Res. 64, 168-173.

Widerstrom-Noga, E., BieringSorensen, F., Bryce, T., Cardenas, D. D., Finnerup, N. B., Jensen, M. P., Richards, J. S., and Siddall, P. J. (2008). The international spinal cord injury pain basic data set. Spinal Cord 46, 818-823.

Wojcik, S. M., Katsurabayashi, S. Guillemin, I., Friauf, E., Rosenmund, C., Brose, N., and Rhee, J. S. (2006). A shared vesicular carrier allows synaptic corelease of GABA and glycine. Neuron 50, 575-587.

Wolfe, S. Q., Garg, M., Cumberbatch, N. M., Furst, C., Martinez, M., Hernandez, M., Reimers, R., Berrocal, Y., Gomez-Marin, O., and Eaton, M. J. (2007). Optimizing the transplant dose of a human neuronal cell line graft to treat SCI pain in the rat. Neurosci. Lett. 414, 121-125.

Yaksh, T. L., Hua, X. Y., Kalcheva, I., Nozaki-Taguchi, N., and Marsala, M. (1999). The spinal biology in humans and animals of pain states generated by persistent small afferent input. Proc. Natl. Acad. Sci. U.S.A. 96, 7680-7686.

Yezierski, R. P., Liu, S., Ruenes, G. L., Kajander, K. J., and Brewer, K. L. (1998). Excitotoxic spinal cord injury: behavioral and morphological characteristics of a central pain model. Pain 75, 141-155.

Yezierski, R. P., Santana, M., Park, S. H., and Madsen, P. W. (1993). Neuronal degeneration and spinal cavitation following intraspinal injections of quisqualic acid in the rat. J. Neurotrauma 10, 445-456.

Yezierski, R. P., Yu, C. G., Mantyh, P. W. Vierck, C. J., and Lappi, D. A. (2004). Spinal neurons involved in the generation of at-level pain following spinal injury in the rat. Neurosci. Lett. 361, 232-236.
Yu, C. G., and Yezierski, R. P. (2005). Activation of the ERK1/2 signaling cascade by excitotoxic spinal cord injury. Brain Res. Mol. Brain Res. 138 , 244-255.

Zeilig, G., Enosh, S., Rubin-Asher, D., Lehr, B., and Defrin, R. (2012). The nature and course of sensory changes following spinal cord injury: predictive properties and implications on the mechanism of central pain. Brain 135, 418-430.

Zhang, A. L., Hao, J. X., Seiger, A., Xu, X. J., Wiesenfeld-Hallin, Z., Grant, G., and Aldskogius, H. (1994). Decreased GABA immunoreactivity in spinal cord dorsal horn neurons after transient spinal cord ischemia in the rat. Brain Res. 656, 187-190.

Conflict of Interest Statement: The authors declare that the research was conducted in the absence of any commercial or financial relationships that could be construed as a potential conflict of interest.

Received: 15 February 2012; paper pending published: 15 March 2012; accepted: 08 May 2012; published online: 31 May 2012.

Citation: Lee JW, Jergova S, Furmanski $O$, Gajavelli S and Sagen J (2012) Predifferentiated GABAergic neural precursor transplants for alleviation of dysesthetic central pain following excitotoxic spinal cord injury. Front. Physio. 3:167. doi: 10.3389/fphys.2012.00167

This article was submitted to Frontiers in Integrative Physiology, a specialty of Frontiers in Physiology.

Copyright (C) 2012 Lee, Jergova, Furmanski, Gajavelli and Sagen. This is an open-access article distributed under the terms of the Creative Commons Attribution Non Commercial License, which permits non-commercial use, distribution, and reproduction in other forums, provided the original authors and source are credited. 